\title{
Tension Pneumothorax in Prehospital Setting
}

\author{
Yagmur Ay, MD; $\odot$ Mustafa Emin Canakci, MD
}

Emergency Department, Eskisehir Osmangazi University, Eskisehir, Turkey

\author{
Correspondence: \\ Yagmur Ay, MD \\ Emergency Department, \\ Eskisehir Osmangazi University, Eskisehir, \\ Turkey \\ Prof. Dr. Nabi Avc1 Boulevard, No:4, \\ Meselik, Odunpazarı, 26040 \\ E-mail: ayyagmur@hotmail.com
}

Conflicts of interest: none

Keywords: emergency department; pneumothorax; POCUS; prehospital

\section{Abbreviation:}

POCUS: point-of-care ultrasound

Received: February 10, 2021

Accepted: February 21, 2021

doi:10.1017/S1049023X21000479

(C) The Author(s), 2021. Published by

Cambridge University Press on behalf of the

World Association for Disaster and Emergency Medicine.
Ay Y, Canakci ME. Tension pneumothorax in prehospital setting. Prehosp Disaster Med. 2021;36(4):498.

To the Editor:

We've read the article by Khalil, et al entitled "Randomized Controlled Trial of Point-ofCare Ultrasound Education for the Recognition of Tension Pneumothorax by Paramedics in Prehospital Simulation" with great interest. ${ }^{1}$ The investigated disease is one which timesensitive intervention has an enormous effect on patient mortality. Thus, getting better at prehospital management of tension pneumothorax becomes paramount of importance.

But while reading this article, there is a point which has caught our attention.

In the study design, one of the groups was educated how to spot pneumothorax only in point-of-care ultrasound (POCUS) and not a complete evaluation of a patient with shock. ${ }^{2}$ That might lead said group to lean on looking for pneumothorax before any other condition that could lead to shock. This could be another explanation for why the "US intervention" group spotted pneumothorax before the control group and not any superiority of one group over another at arriving to the correct diagnosis.

Although the researchers specifically mentioned the diagnosis of tension pneumothorax, there is no different approach for POCUS with simple pneumothorax.

Nevertheless; today we knew that POCUS made diagnoses more accurate and faster in the emergency department, but showing the effect on prehospital management is equally important for better patient care. ${ }^{3}$ For that, we would like to thank the authors for their contribution to the literature.

References

1. Khalil PA, Merelman A, Riccio J, et al. Randomized controlled trial of point-of-care ultrasound education for the recognition of tension pneumothorax by paramedics in prehospital simulation. Prehosp Disaster Med. 2021;36(1):74-78.

2. Husain LF, Hagopian L, Wayman D, Baker WE, Carmody KA. Sonographic diagnosis of pneumothorax. $J$ Emerg Trauma Shock. 2012;5(1):76-81.

3. Atkinson P, Bowra J, Lambert M, Lamprecht H, Noble V, Jarman B. International Federation for Emergency Medicine Point-of-Care Ultrasound Curriculum. Can J Emerg Med. 2015;17(2):161-170. 